\title{
Analysis of Quality of Life Domains in Emergency Hospital Services Personnel. Case Study:
} ICU Medical Team

\author{
Elena Sandu \\ PhD Cand. - ICCV (Research Institute for Quality of Life), Romanian Academy- Romania \\ Assistant Professor - Spiru Haret Faculty of Sociology-Psychology of Bucharest - Romania \\ Clinical Psychologist - Clinic of Anesthesia -Intensive Care Unit (ICU), \\ Emergency University Hospital of Bucharest - Romania \\ sandu.elena@gmail.com
}

DOI:10.5901/mjss.2014.v5n22p433

\begin{abstract}
Based on the demarcation professional group of which we want to investigate in the sociological perspective, we emphasize that our work is part of a multidisciplinary approach generated by very complex professional roles of the participants in our research. We note that the multidisciplinary aspect is associated with the presence of elements of the sociology and psychology confluence, however, we maintain the appearance of multi-disciplinary research approach towards the conceptualization and sociological operationalization of social relations and psychological impacts in the investigated facts. Medical practice is a mix of relationships, facts, phenomena and socio-medical processes subordinated to a major subsystem of society: health care system. Coming out of the sphere of medical sociology specific topics, we decided circumscribing our research field outside medical social relations such as: socio-cultural determinants of health and illness, the sociological and psychological aspects of the therapeutic relationship physician-patient, medicine as a social institution, social aetiology of disease, etc. We restricted the research to a well-defined social environment: hospital emergency medical clinic called ICU and specific issues arising from professional roles of social actors (doctors and nurses) working in this area. More specifically, we wanted to investigate sociological and psychological aspects of these roles in interaction with specific professional environment, from a dual perspective. First, we have investigated an objective perspective of medical team: access to professional development, access to socio-emotional leaders with recognized medical skills, access to medical information technology and performance, and in terms of factors (professional activities / relationships) that are specific to generate satisfaction of medical practice in the Intensive Care Unit. Second, we have investigated a subjective perspective: interaction of personality traits with job satisfaction and individual system of reference values. The investigation carried out on the two social groups- physicians and nurses- have the form of a qualitative research through interviews and questionnaires, on a small sample of subjects, and is a preliminary testing of a comprehensive future research. This paper is made and published under the aegis of the Research Institute for Quality of Life, Romanian Academy as a part of programme co-funded by the European Union within the Operational Sectorial Programme for Human Resources Development through the project for Pluri and interdisciplinary in doctoral and post-doctoral programmes Project Code: POSDRU/159/1.5/S/141086.
\end{abstract}

Keywords: Emergency Medical Services, Professional Development, Medical Leaders, Professional Activities / Relationships, Medical Practice Satisfaction, Personality Traits- Job Satisfaction - Reference Values System, Interviews

\section{Introduction}

This paper is made and published under the aegis of the Research Institute for Quality of Life, Romanian Academy as a part of programme co-funded by the European Union within the Operational Sectorial Programme for Human Resources Development through the project for Pluri and interdisciplinary in doctoral and post-doctoral programmes Project Code: POSDRU/159/1.5/S/141086.

ICU (gr. "therapeia": to heal, to care") is the specialty of intensive medicine in which the patients in a very severe state are permanently assisted by medical staff in special wards ("resuscitation"); considered medical departments of maximum emergency. The patients admitted are patients with altered vital functions or damaged organs which put their lives at risk (life-threatening) and who require continuous medical monitoring and/or support of vital functions. 
From a functional and organizational perspective we note some distinct characteristics of the medical environment in the Intensive Care Unit: complex, invasive and rapid medical techniques, modern medical technology, mechanical support of human vital functions, very little communication time with the patient, fast medical maneuvers, high risk of therapeutic maneuvers, patients with significantly impaired functional autonomy, high and permanent turnover of the number of clinical cases, medical casuistry with a high degree of gravity, high number of deaths in patients.

In this functional environment, the human socios has specific characteristics.

a) Quality of life of patients is presented in a clarifying summary: PTSD with prevalence between 17 and $22 \%$ among survivors of ICU, according to a meta-analysis (Davydow DS., Gifford JM., Desai SV., Needham DM, Bienvenu OJ., 2008) which took account of studies in the U.S., UK and several European countries. Other studies also consider other psychological consequences (Jackson JC., PsyD, Mitchell N., Hopkins RO., PhD, Criticalcare Database, 2009) of the psychotraumatizing environment of the ICU: delirium $80 \%$, cognitive deficits $70 \%$ at discharge, $45 \%$ after 1 year, depression $25-50 \%$ at discharge, $26-33 \%$ at 6 months (a study in 13 ICU units), $58 \%$ at 2 years, $37 \%$ still taking antidepressant medication 2 years after discharge, anxiety 23-41\%, with generative mechanisms: organ dysfunction, medications, pain, sleep deprivation, caused by specific ICU (Intensive Care Unit) treatment, activation of stress by means of the hypothalamic-pituitary axis, hypoxemia, transmission dysfunctions of the neurotransmitters due to brain injuries, especially traumatic stress disorder.

b) Quality of the medical staff's life is related to the activity with the patients, but has dynamic aspects specific to a distinct professional society. The medical doctors are not only social actors who have contact and intervene in man's relationship with the disease, with health, with dead or human suffering. The life of a professional category depends on the functional specificity of the professional environment, on the social mechanisms that intermingle roles and substantiate professional statuses, on the choices and decisions using the contens of the profession, on the values and characteristics of the social group and on the values and personality traits of each individual in the group. All this complex structure comprises multiple domains in which the quality of life can be assessed, measured and changed.

In research literature, the concept of quality of life involves definitions which present its components and areas of applicability, some of them pointing out the advantage of multidisciplinarity of its content, others emphasizing the dual valence, subjective-objective, of the indicators measured. This concept was the core of political, ideological, philosophical and sociological concerns in Western capitalism in the 60s - 70s in Romania being introduced in the 70s - 80s (Zamfir, C., 1976).

The structure of the quality of the medical staff's life, targeted by our research is based on several main approaches to the concept of the quality of life:

a) A complex and comprehensive definition of the quality of life expresses the determinant-defining elements (welfare, human development, quality of society, social exclusion / inclusion, etc..), which means it will include: physical conditions, social, economic cultural, political, health status and so on in which people live, the content and nature of the activities that they perform, the characteristics of relationships and social processes in which they participate, the goods and services that are available, the consumption models adopted, lifestyles, assessment of circumstances and outcomes of activities performed, subjective states of satisfaction / dissatisfaction, happiness, frustration, etc.. (coord. Marginean, I. Balasa, A., 2005).

From this approach we extracted for this research paper the following social indicators concerned: research subjects' perception on the content and nature of activities, satisfaction with the results of activities performed, social relationships in the professional group concerned (doctors in ICU) peer relationships and relationships with people who can provide support / expertise (group leaders), impact on lifestyle (leisure, time spent on family, friends, their development).

b) Another definition of the concept useful in addressing this research is that of Constanza, R. (2008), according to whom the concept of quality of life is "the degree to which the objective needs of the individual are met in relation to subjective, individual or group perception on welfare". The author describes the objective needs in relation to subsistence, reproduction, security, affection, and so on, while the subjective perception aims at happiness, satisfaction with life and personal utility.

From this approach we extracted for our research work the following social indicators concerned: the social role in the family (type of emotional / financial support assumed), the perceived level of integration, cooperation and emotional support in the professional group, the perceived level of the ability of empathy, of professional stress management, of personal growth. 
c) The approach in terms of "capabilities" of the concept of quality of life according to Nussbaum \& Sen (1993), expands the content of the concept from resource to its ability to obtain valuable functionality (the ability of a person to gain valuable acts or reach valuable states). In his approach, Sen says that life is a combination of "states and actions" and that the quality of life is measured by, "the capability to obtain valuable functionality". Functionalities represent "parts of a person's mood - in particular, various things that the person succeeds to represent or do throughout their lifetime". This approach in terms of capabilities and functionalities focuses on individual personality and extends the concent of the quality of life beyond resources, goods, wealth, etc.

From this approach we extracted for this research paper the following social indicators concerned: the subjective social content (eg, job satisfaction, etc..) and the objective content (eg access to medical technology, to educational resources, etc..), motivation, perception on the professional choices and decisions.

d) In continuation of this approach, Alkire (2008) brings on a clarification of the concept of quality of life: the quality of life derives from emotional states, and these states are not limited by material means.

Based on the extension of the concept of quality of life towards individual personality and states of mind, we decided to use variables derived from the personality of our research subjects (personality and temperamental traits) and from their reference value system. The socialization process of each subject formed sets of individual values that will influence the choices and preferences (eds.Voicu, B., Voicu, M., 2008). Thus, the indicators covered by our research are: the level of emotional capacity, the level of activism and the type of reactivity to the environment (primary type vs. secondary type, after Berger's G. typology (1950). From the perspective of the reference value system, we considered individual pro-social orientation focused on humanitarian group values and communion (traditional values) vs. pro-technology, progressive individual orientation focused on individualistic group values and competency-competitive (survival values).

This research has covered the range of areas and indicators of quality of life status by means of qualitative methods. This enabled the development of case studies included to outline the specificity of profession outside and inside the human being (Atkinson, R., 2006) who is committed to practice in a specialty so complex and difficult to describe in universal medical landscape: ICU.

\section{Method: Type of research: qualitative \\ Participants}

Incorporated analysis units: 12 practicing medical doctors in the ICU medical department, aged between 35 and 46 years old, amongst whom 9 women subjects and 3 male subjects. The professional seniority of the 12 subjects is between 10 and 20 years.

\section{Research methodology (data sources and research methods)}

1) Interviews - semi-structured, intensive and comprehensive, based on a depth interview guide.

In our research, these interviews had an exploratory purpose. We are currently in the process of selecting a representative sample of the same professional category, the sample within which the problems identified in our series of interviews were structured on specific areas of analysis, so as to allow for the statistical data processing. Statistical reporting (along with the data from our qualitative research extension) is destined for the awareness (Babbie, E., 2010) about the quality of life in the medical profession, for the area of social policies implemented in the medical system and health programs.

\section{2) Observation - direct and participatory}

Direct observation protocol included: types of professional behavior and dynamic of roles between social actors in the same professional group, observing the hierarchical relationships and the equal roles, and the implications of social status in the patient-physician-patient's caregiver relationship.

Participatory observation was facilitated by the researcher assuming a functional role within the organization, in this case, the role of psychologists participating in the interactions between the social actors involved: physicians, other members of the healthcare team, nurses, patients and their social or emotional support groups. Another benefit of the participation is the one pointed out by Michael Bloor (1997), in the sense of increasing the research depth over the sociological issues of health and medicine due to the pre-existing relation between the researcher and the practitioners. 
3) The testing method - an evaluation test was used to reveal the dominant temperamental traits (Joues, J. P.,2000).

\section{Materials}

1) The interview-guide form: it contained items structured on 6 dimensions, operationalized in a total number of 40 indicators of state and level, as following :

a) Socio-demographic data: 1. age, 2. gender, 3. medical specialty, 4. professional degree, 5. work seniority, 6. type of work contract, 7. dwelling house (congruence "residence-place of work", dwelling place level of satisfaction), 8. marital status, 9 . role in the personal family system, 10 . wages linked level of satisfaction, 11 . congruence level between the real and the expected level of remuneration.

b) History and self-perception in the profession: 1. current level of professional satisfaction, 2. another place of work (and the related satisfaction level), 3. the motivation in choosing this profession, 4.key-sources of individual interest and professional attraction in this type of medical specialty, 5. key-sources of individual difficulty and stress in this type of medical specialty , 6. fields of attraction and difficulty at the beginning of the carrier (technology and medical techniques, information, professional regulations and tasks, professional relations), 7. the individual time necessary for the adapting to this difficulties, 8. current perception and affinity/personal abilities for certain fields in this medical specialty (medical technology, professional information, professional expertise, professional relations, regulations and tasks, medical techniques), 9. the impact in time of the profession over the following fields: spare time, leisure time with significant persons/family, duration and quality of sleep, the self-perceived level of the personal health, the self-described level of personal energy, emotional sensibility, the capacity to empathize and the ability to communicate with other social participants (patients, colleagues and significant persons), the ability to manage the professional stress. 10. the perceived current level of these indicators.11. the sign of future professional expectations in the current conditions.

c) Personality self-perception: 1. personal preoccupations and interests, 2. self-described type of personality (introvert or extrovert focusing, emotional or action-driven style), 3. individual strategies to cope with stress, 4. sanogenetic individual behaviors, 5 . non- sanogenetic individual behaviors

d) Carrier development: 1. preferred strategies to develop carrier, specific to the field, 2. individual access level to the offer of education services and professional improvement, 3. the level of individual satisfaction for the offer of education services and professional improvement, 4. types of obstacles related to carrier development/professional improvement.

e) The commitment towards the progress and personal development: 1. personal benefits of human development generated by practicing this profession, 2 . investments made for the sake of personal progress, 3. types of obstacles against personal development.

f) Individual perception over objectives and values: 1. personality traits that ensure the professional success, 2 . the objectives necessary to obtain the professional competence, 3. social and personal values that are associated to competence and professional success, 4 . individual expectations over the objectives and behaviors of formal leaders. 5 . real level of satisfaction over the goals and behaviors of the formal leaders, 6. personal axiological scale.

The indicators had, from case to case, three types of answers: binary choices, multiple choices or self-rating on the Lickert scale.

2) The G. Berger Character logical Questionnaire is a questionnaire generated by the character logical French-Dutch school:

a) three fundamental factors of the individual characterial nature (Emotionality vs. Non-Emotionality, Activism vs. NonActivism and Resonance, expressed as Primarity vs. Secundarity); b) six complementary factors (Extent of the conscience field, Genre polarity, Avidity, Sensorial interests, Tenderness and Intellectual passion).

In our qualitative approach, out of the 90 items in the test, we used the Romanian adaptation of the 3 fundamental factors (which contain a total number of 30 items):

a) Emotionality vs. Non- Emotionality (10 items) - the level of the psychical sensibility to emotions or interior and exterior disturbances

b) Activism vs. Non-Activism (10 items) - the individual's easiness to act, to swim into action. 
c) Resonance (Primarity vs Secundarity) (10 items)- repercussion, the resonance of an event over the individual mentality The three temperamental factors (of 10 items each) use the binary rating.

\section{Procedure}

Throughout the months of May - June 2014, direct, half-structured and intensive interviews have been performed, based on the interview guide, with an average of 3 hours per subject.

The G. Berger Character logical Questionnaire needed an average of 5-10 minutes to be integrally filled in by the subjects of the research.

\section{Results}

The purpose of our research was to cover comprehensive fields of professional activity, interpersonal relational levels and psychic adjusting mechanisms with effects in the ICU socios field. The following manifest "fields" of the life quality were identified and structured:

a. the relation,, factual variables - economical status", b. perceived quality of life, c. work (the socio-functional environment and the participation), d. professional human environment

\section{Findings of „,Factual Variables - Economical Status”}

The level of the economical status is referred to as being higher with the investigation subjects that have a professional activity of approx. 15-20 years as compared to the subjects with a professional activity of 10-15 years.

The marital status and the dwelling place satisfaction do not trigger alone the economic status satisfaction, because the interests for the purchase of goods and other consumption products taking into account the specificity of the age and of personality.

The subjects with small children perceive their economic status as being insufficient.

Another significant aspect is that of the unitary reference by all subjects of the investigation to the level of financial satisfaction through remuneration, as being unsatisfying and incongruent with the quality and responsibility of the work performed.

In what concerns the dynamics of the family roles, the individual assumed support type in the family (mostly emotional vs. mostly financial support) reveals a low satisfaction level over the economical status with the subjects that contribute financially to the family life. The type of emotional support is associated, with the subjects that assumed it in the personal family, with the less important concern and interest for the financial aspect.

\section{Finding of „Perceived Quality of Life”}

Concerning the life quality in the fields: free time, leisure activities, time spent with the significant persons (family, friends), personal health, emotional sensibility, subjects showed a significant decrease in all explored items, placing the current level of these aspects, with no exceptions, as being unsatisfying.

As a compensation, it was revealed that the subjects perceive a higher level of satisfaction in what concerns the quality of relations with significant persons, the empathy capacity and the communication skills with colleagues, patients and personal family; the more considerable the professional experience and the duration of the work activity are, the stronger the perception of the qualitative increase in these fields.

The extravert vs. the introvert type of personality and the emotion driven vs. the action driven personality types did not reveal influences on the increase in time of the self-perceived level of empathy or communication ability.

\section{Findings of "Work (the socio-functional environment and the participation)"}

The research revealed a differentiation of the current level of professional satisfaction referred by the subjects, depending on the motivation in choosing their profession; the subjects that stated a higher level of professional satisfaction being those 
that chose the profession from the desire to be a medical doctor and to cure, followed by the subjects that chose the profession because their considered it adequate to their own personality.

The subjects with the lowest degree of actual declared satisfaction proved to be the ones that chose the profession as result of significant losses (deaths or severe illnesses in the family) and those that chose this profession in order to "save lives".

The key sources for personal attraction toward this type of medical specialty were "the challenge", "dynamic adrenalinepacked activity"," the complex and difficult casuistry" and "the satisfaction of solving medical cases with low chances of survival". These represented, according to the subject statements, a substantial moral, intellectual and emotional compensation for the unsatisfactory level of wages. This compensation is valued by the subjects with a rational and competitive orientation more than by those with a predominantly emotional orientation and who prefer to work within a team.

The study subjects have considered the level of difficulty and risk of the composing elements of professional environment (medical technology, medical techniques particular to ICU, professional rules and tasks) as a professional stress sources only by those who share the conviction that they do not poses technical skills and who do not have a predominantly rational and competitive work style.

\section{Findings of "Professional Human Environment"}

The subjects who proved a higher self-perceived level of integration in the professional group have been identified as those having a rational and problem-solving working style, as well as those who value the extraprofessional areas of life or who invest in personal development (human evolution). The level of integration in the professional group was perceived individually as being unsatisfactory by the subjects who do not invest time in the traditional values (family) and who show an affinity for competiveness and perfectionism.

It should be noted that the subjects who consider the formal leader as being emotionally unsupportive have proven an unsatisfactory level of personal integration in the professional group, if they are centered on emotion, while the subjects who are action oriented are affected only if they feel that the formal leader does not appreciate positively the quality of their work and their professional decisions.

The individual expectations of subjects concerning the objectives and behaviors of formal leaders have varied according to the degree of congruence with the sets of personal values of each subject and with their predominant orientation (traditional vs. progressive values)

\section{Discussion - extrapolations and criticism}

Following the assessment of the data yielded by the content of interviews we consider as important the differences highlighted by the four following aspects: a. the experience and the active time spent in this profession, $b$. the temperamental traits and the type of personality, c. the intrinsic motivation for choosing this profession, $d$. the sense and individual meaning of personal existence

The study has exposed qualitative aspects with a descriptive and explicative signification.

An important shortcoming is the lack of statistical power of the selected group, which did not allow a processing which would pinpoint the significant correlations between the explored variables.

The qualitative data of sociologic and psychological type that have been brought forward form - at this point- the introductive and exploratory part of a vaster study and their purpose is:

a. to allow a comprehensive understanding of the medical field and of the implications of its functional specificity on the social relationships and on the psychism and the behaviours of the social players involved (Goffman, E., 1961a)

b. to select the relevant indicators.

The replication of interviews on more representative groups can bring about contributions to programs designed to diminish the professional burn-out particular to the healthcare professions and to restructure certain functional and administrative aspects existing in the current medical system. 
Another shortcoming of the current level of the study is the impossibility to highlight gender differences. Although the study has also taken into consideration aspects that pertain to the masculine vs. feminine roles, it has not set them as a priority purpose of the research.

Some other areas which were insufficiently explored are those related to the feeling of personal security at the workplace and to the society perception of the role, status and quality of work in ICU.

In conclusion, the professional group of the ICU medical practitioners is faced with specific professional difficulties; it is rendered vulnerable by the intensive type of the medicine they practice and by the psychological impact of the associated medical cases.

Among the primary coping resources the following can be mentioned: $a$. the type of personality, b.time spent and experience in this professional activity, c. the set of individual values, $d$. the individual intrinsic motivation for working in this field.

\section{References}

Alkire, S..(2008). The Capability Approach to the Quality of Life. http:// www.stiglitz-se -fitoussi.fr/ documents/ capability_ approach.pdf

Atkinson, R. (2006).Povestea vieții. Interviul. Seria „Collegium. Sociologie. Antropologie”. Trad. S. Năstuță. Polirom. lasi. pp. 7-10, 43-77

Babbie, E. (2010). Practica cercetării sociale, Seria „,Collegium.Sociologie. Antropologie”, Trad. G. Sergiu, G. Jiglau, M. Andriescu. Polirom, lasi. pp.511-542

Berger, G. (1950). Questionnaire caractérologique. PUF.Paris

Berger, G.. (2010). Tratat practic de cunoastere a omului, Ed. Univers Enciclopedic Gold, Bucuresti

Bloor, M. (1997). Adressing social problems through qualitative research. In Silverman, D. (ed.). Qualitative Research: Theory, Method and Practice. Sage. London .pp.220-238

Costanza, R. et all.(2008). An Integrative Approach to Quality of Life Measurement, Research, and Policy.S.A.P.I.EN.S. No.1/2008

Davydow DS., Gifford JM., Desai SV., Needham DM, Bienvenu, O.J.( 2008). Posttraumatic stress disorder in general care unit survivors: a systematic review. rev. General Hospital Psychiatry. Sept.-Oct.Vol.30(5). pp. 421-434.

Goffman, E. (1961a). Asylums. Doubleday Anchor. New York.

Jackson JC., PsyD; Mitchell N.; Hopkins RO., PhD. (2009). Cognitive Functioning, Mental Health and Quality of life in ICU Survivors: An Overview. rev. Critical Care Clinics. July. vol. 25 (3): pp. 615-628 http://www.d.yimg.com/kg/groups/167749867/771940762/name/cognitive_function_quality_life.pdf

Joues, J. P. (2000). Caracterologia. Cele 10 sisteme de bază. Trad. R. Glovaschi. Teora. Bucureşti.pp.132-152

Marginean, I., Balasa, A. (coord.). (2005). Calitatea vietii in Romania, ed. 2. revazuta si completata. Expert. Bucuresti. pp.33-60

Nussbaum, M., Sen, A.K. (eds.).(1993). The Quality of Life (Wider Studies in Develoment Economics). Oxford University Press. New York. pp 8-26

Voicu, B., Voicu, M. (eds.).(2008). The Values of Romanians: 1993-2006. A sociological perspective. Institutul European. lasi. pp.11-22

Zamfir, C.(1976). Indicatorii sociali de stare si indicatorii sociali de satisfactie. Revista Viitorul social. Nr. 3

WVS Database. World Values Survey Wave 6: 2010-2014. www.worldvaluessurvey.org/WVSOnline.jsp

Yin, R.K. (2005). Studiul de caz. Designul, colectarea şi analiza datelor. Trad. V. Alupoaie. Polirom.lasi 
